\section{Ficção científica, percepção e ontologia: e se o mundo não passasse de algo simulado?}

\author{
Science fiction, \\ perception, and \\ ontology: is the world \\ fake?
}

CARDOSO, C. F.: Ficção científica, percepção e ontologia: e se o mundo não passasse de algo simulado?

História, Ciências, Saúde - Manguinhos, v. 13 (suplemento), p. 17-37, outubro 2006.

O artigo trata de uma temática que gerou diversos filmes desde o final da década de 1990: a noção de que o mundo onde se moviam as personagens, bem como eventualmente as personagens mesmas, revelavam ser uma simulação. Tal temática foi grandemente influenciada pelos avanços da informática no domínio da assim chamada 'realidade virtual' e cumpriu funções narrativas variadas. Em especial, abriu-se em certos casos para interrogações típicas da ontologia e/ou da metafísica, relativas à realidade ou irrealidade do mundo exterior, e serviu para explorar uma temática de grande presença na ficção científica desde o surgimento da tendência cyberpunk em 1982: a dos poderes corruptores e manipuladores que interferem com a liberdade e a iniciativa dos indivíduos.

PALAVRAS-CHAVE: realidade virtual; ficção científica; ontologia; utopia; distopia.

CARDOSO, C. F.: Science fiction, perception, and ontology: is the world fake? História, Ciências, Saúde - Manguinhos, v. 13 (supplement), p. 17-37, October 2006.

The article explores a topic that inspired a number of movies in the late 1990s: characters who are eventually found to live in a fake world and even to be fake themselves. Heavily influenced by advances in the computer field of so-called virtual reality, the topic has played different narrative roles. In particular, the films in some cases allow us to raise ontological or metaphysical questions about the reality or unreality of our external world, and have delved into a subject quite common in science fiction ever since the 1982 appearance of the cyberpunk trend: corruptive, manipulative powers that interfere with individual freedom and initiative.

KEYWORDS: virtual reality; science fiction; ontology; utopia; dystopia.
Ciro Flamarion Cardoso

Centro de Estudos

Interdisciplinares da Antiguidade - UFF

Rua Teófilo Rodrigues, 22 apto. 504

24210-490 Niterói - RJ - Brasil

ciro@cruiser.com.br 
$\mathrm{E}$ ste artigo pretende indagar a razão de, desde os últimos anos da década de 1990, terem-se produzido filmes como Cidade das sombras (Alex Proyas, 1997), 13ํo andar (Josef Rusnak, 1998), The Matrix (Larry e Andy Wachowski, 1999), Existenz (David Cronenberg, 1999) e, mais recentemente, A ilha (Michael Bay, 2005), bastante diferentes entre si mas unificados por uma temática central análoga: descobre-se que o mundo em que vivem, agem e se movem as personagens é, na verdade, falso - mera simulação. Esse tema se apresenta de diferentes formas. Assim, por exemplo, em $13^{\underline{o}}$ andar as personagens são de fato, na sua maioria, bem como seu meio ambiente completo, uma simulação gerada em computador, funcionando, no essencial, em circuito fechado. Em $A$ ilha, além de que a simulação se dá sobre bases distintas e a serviço de atividades de clonagem voltadas para transplantes de órgãos, existe lá fora um mundo maior, em princípio acessível, mas evitado pelos moradores do microcosmo que o filme descreve, já que estes acreditam, erroneamente, ser tal mundo exterior inabitáv el, com a exceção única de uma ilha. Seja como for, trata-se de filmes marcados por algumas das mais tradicionais temáticas ontológicas - a indagação sobre ser ou não real o mundo exterior a cada indivíduo, e a pergunta sobre até que ponto o que se julga real deriva das percepções sensoriais, por sua vez dependentes de sentidos muito imperfeitos.

\section{A ficção científica como gênero}

Numa enciclopédia recente de ficção científica, publicada em 2001, propõe-se uma definição do gênero que tomarei como ponto de partida:

A ficção científica é uma forma de literatura fantástica que tenta retratar, em termos racionais e realistas, tempos futuros e ambientes que diferem dos nossos. No entanto, mostra estar consciente das preocupações dos tempos em que é escrita e provê um comentário implícito sobre a sociedade contemporânea, explorando os efeitos, materiais e psicológicos, que qualquer tecnologia nova pode ter sobre ela. Quaisquer mudanças que tiverem lugar na sociedade enfocada, e também quaisquer acontecimentos futuros que forem extrapolados, deverão basear-se em uma teoria, científica ou não, encarada em forma comedida e considerada. Os autores de ficção científica usam seus ambientes estranhos e imaginativos como um campo de prova para novas idéias, examinando em forma plena as implicações de qualquer noção que propuserem. (Mann, 2001, p. 6)

Diversos tópicos podem ser derivados de uma análise dessa definição:

1) a ficção científica não é, hoje em dia, um gênero unicamente literário: é também cinematográfica, televisiva, de história em 


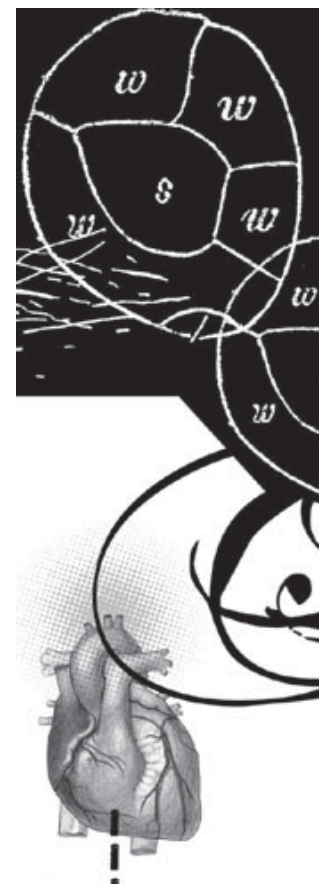

quadrinhos, está presente em jogos de computador e na produção de bonecos, camisetas e muitos outros objetos mercadológicos. Mas, sem dúvida, ela começou como gênero literário; e integra, também indubitavelmente, o campo de um gênero mais amplo, o fantástico;

2) a racionalidade, o realismo, a busca de apoio em alguma teoria que não pareça descabelada, com exploração das implicações do que for postulado: eis aí pontos que diferenciam a ficção científica, por exemplo, do horror ou do maravilhoso, dentro do conjunto maior que constitui o gênero fantástico. Vamos exemplificar com um tema específico: o deslocamento no tempo. Três episódios de 1977 da série estadunidense, de terror ou fantástica conforme os episódios, Dead of night, dirigidos por Dan Curtis, foram lançados no Brasil em vídeo sob o título Trilogia macabra (Taipan). No primeiro deles, com o ator Ed Begley, Junior, intitulado "A segunda chance", um rapaz adquire e restaura um velho carro e, ao estreá-lo numa antiga estrada de terra abandonada, volta a um passado anterior a seu nascimento, décadas antes do presente. Tal volta não é explicada e parece provocada pelo velho carro e pela velha estrada. Isto não é ficção científica, mas sim, pertence ao gênero geral do fantástico. A máquina de explorar o tempo, romance de H. G. Wells (1895), pelo contrário, é ficção científica: a máquina, mesmo sendo absolutamente imaginária, dá uma aura de seriedade explicativa à viagem no tempo; e a obra também se baseia no evolucionismo de Darwin e em teorias que tinham curso no final do século XIX, em que o tempo era visto como uma 'quarta dimensão', em conjunto com as três do espaço;

3) o futuro aparece como temporalidade preferencial da ficção científica, juntamente com ambientes insólitos. É impossível, porém, escrever efetivamente sobre o futuro (Bova, 1993, p. 295); mesmo assim, existe, sem dúvida, um elemento de extrapolação preditiva em bom número de escritos e filmes de ficção científica. Comentando este tópico, a escritora Ursula Le Guin afirma que tal modalidade de ficção científica costuma, em geral, desembocar onde desembocava o Clube de Roma: "em algum ponto entre a extinção gradual da liberdade humana e a extinção total da vida terrestre" (Le Guin, 1976). A série de filmes que motivou este artigo, continuadora de uma linha inaugurada em 1982 com a tendência conhecida como cyberpunk, situa-se exatamente aqui, entre as obras que prevêem a interferência na liberdade individual de alguma força manipuladora;

4) o futuro como cenário da ação, ou ambientes insólitos ficcionais, são, mais freqüentemente, instrumentos para explorar aspectos do presente social especulativamente, o que significa, entre 
outras coisas, empreender tal exploração mediante o emprego de metáforas e tomar como ponto de partida, com freqüência, atitudes como perguntar 'o que aconteceria se': em outras palavras, é própria do gênero a procura do que Bertolt Brecht chamava de 'efeito de estranhamento', um ângulo de abordagem que permite o tratamento de uma determinada situação de modo que ela seja reconhecível mas, ao mesmo tempo, pareça insólita, estranha, 'outra';

5) a ficção científica, ao falar do futuro ou transferir-se a ambientes e situações estranhos, age como 'campo de prova para novas idéias': com efeito, trata-se de setor mais aberto a isto do que qualquer outro dentre os que integram a cultura popular ou de massa, e Ursula Le Guin, ao refletir sobre o gênero em que atua, o vê situado principalmente neste terreno, o do experimento com idéias (thought-experiment), a serviço muito mais de uma descrição de aspectos do presente (mesmo se este aparecer disfarçado de futuro) do que de uma autêntica predição, mesmo se esta for feita (Le Guin, 1976);

6) o ponto mais fraco da definição de George Mann com que começamos consiste em isolar a questão do impacto tecnológico como algo central: tal opção funcionaria relativamente bem até a primeira metade do século XX; posteriormente, haveria exceções muito numerosas, devidas à presença crescente de uma ficção científica soft (isto é, cujo ponto de referência científico ou pseudocientífico seja alguma das ciências humanas e sociais) ao lado da modalidade mais antiga, a ficção científica hard (que busca referência em disciplinas como Física, Química, Astronomia ou Biologia, por exemplo, bem como em tecnologias - ou pseudotecnologias - pensadas em função das mencionadas disciplinas), ou a ela se mesclando.

A respeito da relação da ficção científica com a ciência, seria possível achar facilmente declarações que parecem absolutamente contraditórias. Assim, ouçamos, por um lado, o veterano Ben Bova: "Quando eu falo de ficção científica, quero dizer uma ficção em que algum elemento de ciência ou tecnologia futura seja tão integral à narrativa, que esta entraria em colapso se o elemento científico ou tecnológico fosse removido" (Bova, 1993, p. 293).

Em contraste, o romancista e crítico britânico Brian Aldiss diz que, do mesmo modo que a literatura sobre fantasmas não se destina aos fantasmas, a ficção científica não se destina aos cientistas. James G. Ballard, por sua vez, afirmou em 1969 ser ridícula a idéia de que as revistas típicas da literatura de ficção científica tivessem algo a ver com ciência, bastando examinar Scientific American ou Nature, que de fato são revistas científicas, para que a diferença ficasse patente (Clute \& Nicholls, 1995, p. 312). 
Não há dúvida, aliás, de que a ficção científica, em qualquer de seus veículos, sempre esteve eivada de erros científicos, freqüentemente com pleno conhecimento de causa de quem os cometesse: este seguia alguma razão ficcional, argumentativa ou simplesmente de busca de efeito para introduzir o erro, pois estamos num terreno ficcional, não na produção de tratados ou manuais científicos. H. G. Wells, por exemplo, um romancista dotado de razoável formação científica, sabia perfeitamente ser a invisibilidade, ao que tudo indica, impossível; além de que, caso se tornasse possível, um homem invisível seria necessariamente cego! No entanto, o que ele queria, em seu romance O homem invisível (1897), era fazer com que o leitor aceitasse, durante a leitura, a invisibilidade como algo verossímil literariamente, mediante uma pseudo-tecnologia - a descoberta de um preparado químico que, obviamente, não é descrito nem detalhado -, em lugar de, por exemplo, como foi feito na Antiguidade em contexto diferente, mediante o anel mágico de Giges, para então, a partir daquela premissa, examinar, no que é sem dúvida um conto moral, o mergulho do protagonista na megalomania. Em geral, quanto a erros científicos na ficção científica, nós temos o que os franceses chamam de l'embarras du choix. No cinema de ficção científica da década de 1950, por exemplo, abundavam insetos e aracnídeos gigantescos. Ora, um animal dotado só de exoesqueleto quitinoso entraria em colapso sob seu próprio peso caso se tornasse gigantesco; nem poderia mover-se, menos ainda, efetuar as destruições catastróficas que aqueles filmes lhes atribuíam! Na mesma época, apareciam, nos filmes sobre viagens espaciais, meteoritos em chamas: como, na ausência de oxigênio do espaço sideral? A não ser em filmes especialmente cuidadosos, como 2001: uma odisséia no espaço, abundam, mesmo hoje em dia, ruídos de explosões no vácuo espacial em cenas de combate ou em outras circunstâncias: como poderiam ondas sonoras propagar-se no vácuo? Em ficção científica, estamos no terreno da pseudo-ciência e da pseudo-tecnologia com muito mais probabilidade do que no terreno autenticamente científico e tecnológico, embora alguns elementos autênticos possam estar também presentes.

Ao que vou é o seguinte: a ciência, em conjunto com a tecnologia, mais do que um verdadeiro componente, foi um dos principais pressupostos para que a ficção científica surgisse e se mantivesse como gênero no mundo contemporâneo. Tais pressupostos centrais da ficção científica são basicamente três:

1) como ela nasceu primeiro como gênero literário ficcional, supôs a fixação do romance moderno (já bem estruturado ao terminar o século XVIII) e do conto, teorizado por exemplo por Edgar Allan Poe no início do século XIX: isto, sendo um fator muito geral de qualquer literatura ficcional, não precisa ser discutido aqui; 


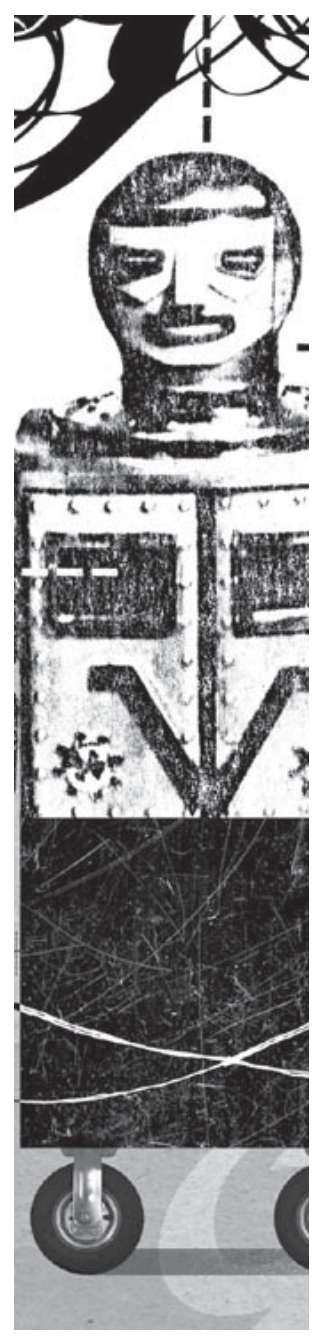

2) a ciência como horizonte de plausibilidade, legitimador de uma visão de mundo nova: a Revolução Científica começa no século XVII, mas demora a influir generalizadamente nas formas de percepção do mundo e das coisas, o que se dá sobretudo a partir da segunda metade do século XVIII e tem seu auge no século XIX e na primeira metade do século XX;

3) em função das revoluções sociais, em especial após 1789, mas também do influxo da revolução científica, há uma mudança radical na percepção do tempo, tanto natural quanto social, bem como uma historicização da sociedade e do próprio universo (mediante a geologia histórica, a teoria da evolução, certas teorias cosmológicas etc.), destruindo as visões cíclicas e trazendo a convicção de que o presente difere do passado e de que o futuro, por sua vez, será diferente do presente (Cardoso, 2003, p. 21).

Jacques Goimard, explorando um importante aspecto do gênero de todo ausente na definição com que começamos, afirma que, tal como qualquer forma de fantástico, a ficção científica comporta um deslocamento da verossimilhança - o que significa exigir maior investimento da configuração da obra no sentido de conseguir uma suspensão da incredulidade do leitor ou espectador -, sendo-lhe específico cumprir uma função mítica (Goimard, 1976, p. 20), numa era de avanço da laicização do pensamento, exatamente por seus pressupostos racionalizantes e científicos (ou pseudo-científicos).

Parece-me que essa função mítica, aliada a uma grande maleabilidade temática, explica a diferença de atitude existente, no tocante ao público, entre a sua posição diante da ficção científica e de outros setores da cultura popular - com exceção, talvez, de certas formas de fantástico que, sem integrarem a ficção científica, também são criadoras de mitos alternativos aos gerados historicamente, como é o caso, por exemplo, do universo imaginado por J. R. R. Tolkien a partir de uma fusão e extrapolação das mitologias celta e germânica. Embora outros setores da cultura de massa tenham tido ou tenham ainda grande sucesso de público, por exemplo, num passado ainda recente o faroeste, e até hoje o romance policial, seria difícil imaginar uma militância dos consumidores de ficção popular, nesses setores, comparável à que se constata no tocante à ficção científica. Um primeiro exemplo pode ser o seguinte: é factível imaginar a formação de grupos de discussão na Internet inspirados por romances policiais, na mesma proporção e entusiasmo, digamos, com que foram suscitados pelo filme The Matrix (1999)? Para dar um segundo exemplo, os trekkies, isto é, os fanáticos da série original Jornada nas estrelas, da década de 1960, e suas ramificações posteriores (outras séries, filmes de longa metragem, romances, fotonovelas, histórias em quadrinhos, objetos variados de marketing etc.) podem contar até mesmo com uma enciclopédia que 
1 Jacques Goimard mostra que essa tendência à mescla crescente da ficção científica com outros elementos da ficção fantástica reflete mutações nas preferências do público do gênero, bem estudado sobretudo no tocante à literatura, menos quanto ao cinema (Goimard, 2002, p. 123-44). sistematiza um mundo ficcional futuro tão complexo como o que as séries, romances e filmes foram criando ao longo de décadas (Okuda, Okuda \& Mirek, 1994). Há coisas similares para o universo imaginado por J. R. R. Tolkien; não existem, porém, com características análogas, para o faroeste ou o romance policial.

O mundo da ficção científica conta, em especial nos Estados Unidos, seu epicentro, com associações numerosas de fãs, algumas das quais publicam revistas artesanais ou semiprofissionais, prêmios próprios (Hugo, Nebula), numerosos congressos e convenções, gerais ou mais especializados (como os dos já mencionados trekkies). Existe, também, uma importante associação de escritores norte-americanos de ficção científica - que, não por acaso, passou a chamar-se, em 1992, Science Fiction and Fantasy Writers of America (Escritores de ficção científica e de fantasia [dos Estados Unidos] da América), reconhecendo, assim, a fusão progressiva da ficção científica com gêneros próximos também integrantes do fantástico, tornando-a uma subcultura menos fechada sobre si mesma do que no passado, em especial a partir de meados da década de $1960 .^{1}$

\section{Ficção científica e mundos simulados}

Um bom ponto de partida pode ser o escritor polonês, recentemente falecido, Stanislaw Lem, já que abordou o assunto da realidade virtual tanto ficcionalmente como em obras não-ficcionais.

Num dos contos reunidos, em polonês, em antologia de 1971, publicada em inglês em 1982, temos o encontro do protagonista, o astronauta Ijon Tichy, com o professor Corcoran, especialista em cibernética. Este último construíra um mundo virtual na forma de certo número de cérebros eletrônicos armazenados em caixas, ligados a um tambor metálico do qual fluíam aleatoriamente para eles impulsos eletrônicos análogos aos inputs sensoriais que os nervos conduzem aos cérebros orgânicos. Corcoran descreve assim a sua criação, em conversa com Tichy em seu laboratório:

- Cada caixa contém um sistema eletrônico que gera consciência, tal como nosso cérebro faz. A estrutura é diferente, o princípio é o mesmo. A similaridade termina aqui, porém; porque nossos cérebros, para dizê-lo assim, estão ligados ao mundo exterior por meio de receptores sensoriais - olhos, ouvidos, nariz, pele etc. Estes, entretanto - disse, apontando para as caixas - contêm seu próprio "mundo exterior" ali dentro.

- Como pode ser? - perguntei. Algo começava a raiar em mim. Eu não o podia perceber perfeitamente, mas aquilo me fez estremecer.

- É muito simples. Como cada um de nós sabe que tem um dado corpo, exatamente aquele e não outro, que está de pé, segurando 
um livro, que as flores cheiram bem? É porque certos estímulos agem sobre nossos sentidos e os nervos conduzem mensagens ao cérebro ... Pois bem. Estas caixas estão dotadas de órgãos receptores que funcionam em forma análoga a nossa visão, olfato, audição, tato etc. E os cabos desses receptores estão ligados como os nervos; mas não ao mundo exterior, como os nossos nervos estão: eles estão ligados àquele recipiente metálico cilíndrico, lá no canto ... O recipiente contém fitas especiais, estímulos elétricos gravados que correspondem ao bilhão ou dois bilhões de fenômenos que a pessoa pode encontrar na vida mais carregada de impressões. Se você levantar a tampa do tambor metálico, verá unicamente fitas brilhantes cobertas de ziguezagues brancos, semelhantes a marcas de mofo sobre o celulóide; entretanto, Tichy, elas são noites meridionais úmidas, o murmúrio das ondas, as formas de corpos de animais, ou o barulho de um tiro de revólver; funerais e bebedeiras; o sabor de maçãs e laranjas, tempestades de neve em noites passadas com a família junto à lareira, ou o pandemônio a bordo de um navio que naufraga; as convulsões da doença, cumes de montanhas, cemitérios - e alucinações daqueles que deliram. Tichy, o tambor metálico contém o mundo! (Lem, 1982, p. 42-43)

\section{Mais adiante em suas explicações, Corcoran esclarece:}

- O destino de minhas caixas de ferro não é predeterminado, pois os eventos contidos no cilindro metálico estão dispostos em fileiras de fitas paralelas e é um seletor que, ao acaso, decide de qual fita o sensor de uma dada caixa vai receber a seguir o conteúdo. Claro que não é assim tão simples, porque a própria caixa pode, até certo ponto, afetar o movimento do seletor, de modo que a seleção só é de todo aleatória quando o ser que eu criei reage passivamente... Mas ele tem livre-arbítrio, limitado unicamente por aquilo que limita o nosso: personalidade, deformidades congênitas, condições externas, o nível de inteligência - não posso entrar em todos os detalhes... (Lem, 1982, p. 44)

As caixas de ferro, obviamente, não têm como descobrir o que de fato são: cada uma delas acredita-se um ser humano, possuidor de uma personalidade própria, individual, e de um corpo igualmente específico com o qual age no mundo enquanto vive. Exatamente como nós, caso o nosso mundo não passasse de uma simulação, ao termos acesso a ele somente por meio da informação sensorial não teríamos como saber tratar-se de um universo simulado. Corcoran evita interferir no sistema que criou, qual demiurgo em miniatura (Lem, 1982, p. 45-50). É Ijon Tichy quem tira a conseqüência lógica do que lhe dissera o cibernético:

- ... Mas então, também é possível que o dono do laboratório empoeirado em que NÓS somos caixas em cima de prateleiras 


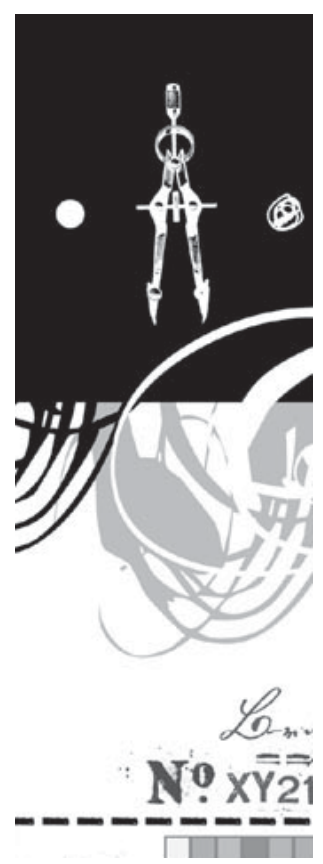

seja, ele mesmo, uma caixa, uma caixa construída por outro cientista de hierarquia mais alta, que tem noções originais e fantásticas... etc., ad infinitum. Cada um desses experimentadores é Deus, o criador de um universo na forma de caixas e do destino delas; sob ele estão Adães e Evas, acima dele, o seu próprio Deus, um degrau acima na hierarquia. (Lem, 1982, p. 50)

Em forma não-ficcional, Stanislaw Lem incluiu em seu ensaio Summa technologiae (1964) uma ampla seção sobre a realidade virtual, por ele batizada 'fantomática' naquela ocasião: lembremo-nos de que a expressão 'realidade virtual' ainda não era usada no início da década de 1960, tendo sido cunhada em 1981 pelo empresário da informática Jaron Lanier e usada pela primeira vez num romance de ficção científica (The Judas mandala, de Damien Broderick) em 1982. Ao ser publicada em polonês, Summa technologiae sofreu forte ataque do filósofo Leszek Kolakovski, que afirmou peremptoriamente serem meros 'contos de fadas' os prognósticos de Lem sobre o que hoje conhecemos como realidade virtual. Por tal razão, numa coletânea mais recente, Lem incluiu o artigo 'Trinta anos depois', em que mostrou que, pelo contrário, seus prognósticos haviam sido perfeitamente sustentados pelos desenvolvimentos posteriores da cibernética no campo da realidade virtual.

Ao abordar filosoficamente a questão em seu artigo, Lem, embora parta de George Berkeley (1685-1753) e sua máxima esse est percepi - existir é ser percebido -, já que só podemos julgar como existente aquilo que nossos sentidos nos permitam perceber, afastase do operacionismo (ou operacionalismo) contemporâneo, avançado pelo eminente físico estadunidense Percy William Bridgman (1882-1961). Isto fica patente em sua crítica à afirmação de Bertrand Russell de que a matéria pode ser caracterizada como aquilo que preencha os parâmetros de sua definição segundo as equações da física teórica. Diz Lem: “a razão simples pela qual não posso concordar com esta opinião é que existem teorias alternativas na física teórica, enquanto a matéria, se ela existe (e eu acho que sim), é uma só" (Lem, 1997, p. 71). O operacionismo é idêntico ao empirismo radical e, para este, as entidades teóricas são construções lógicas levadas a cabo a partir da experiência; entretanto, é impossível, por exemplo, até mesmo começar a empreender experimentos ou medições sobre algo que não saibamos previamente o que seja: existe um hiato lógico necessário entre teorias e dados empíricos (Blackburn, 1997, p. 274).

Como Lem, sou um realista. E, como Mario Bunge, acho o seguinte:

A execução de provas empíricas supõe a existência autônoma do mundo exterior ao sujeito que as executa. Sem este suposto não teria objeto buscar dados por meio de observações, medições ou 
experimentos: bastaria inventá-los ou, mesmo, ignorá-los. Em outras palavras, as operações empíricas supõem o realismo. Em particular, pressupõem que o objeto observado e o instrumento de observação tenham existência independente do sujeito cognoscente. Isto não veda que o experimentador planeje e estabeleça seus meios de observação, valha-se deles para modificar algumas das propriedades das coisas que observa, ou mesmo, fabrique algumas delas, como acontece quando produz novas partículas ou moléculas, novos materiais, ou até mesmo novos organismos. (Bunge, 1985, p. 77)

Bunge deixa claro, porém, não haver como provar que o mundo exista, nem que não exista, a partir da atividade científica. Realismo, anti-realismo, operacionismo etc. não passam de posições filosóficas preferidas a priori, ou resultantes de reconstruções $a$ posteriori de achados científicos no domínio da filosofia da ciência. Não importa, por exemplo, que muitos, equivocadamente, acreditem que uma determinada interpretação da Mecânica Quântica (conhecida como interpretação padrão ou de Copenhague) 'demonstre' a veracidade da posição operacionista, nem que numerosos manuais, livros de divulgação ou a imprensa o repitam ad nauseam: tal interpretação, mesmo sendo a predileta, é só uma dentre muitas, e alvo de críticas razoáveis como qualquer das outras (Bunge, 1985, p. 77-87). Pode-se argumentar racionalmente a favor de qualquer das posturas filosóficas em torno do realismo e do anti-realismo ontológico ou epistemológico; mas é impossível prová-las de um modo que obtenha consenso geral, pelo qual estes debates continuarão conosco no futuro previsível.

Afirmei ser mais razoável, em minha opinião, supor a existência do mundo exterior ao sujeito porque, como mostra Lem em sua ficção e em seus ensaios não-ficcionais - apesar da afirmação em contrário presente, como vimos, no conto de que já falamos em que aparece o professor Corcoran -, há sem dúvida meios racionais que permitam decidir se a 'realidade' que se observa é ou não virtual; ou ainda, por exemplo, se deriva de uma alucinação. Veremos que também no filme que será analisado neste artigo, $13^{\underline{0}}$ andar, e o mesmo acontece no romance em que se baseou, algumas personagens puderam, racionalmente, perceber o caráter simulado de si mesmas e de seu universo mediante certas ações ou experimentos (cf. Lem, 1983, p. 47-50; Lem, 1997, p. 79-85).

Deixando agora de lado os aspectos filosóficos das questões envolvidas pela percepção e pela ontologia, tratemos de explorar, seletivamente, as funções ficcionais da realidade virtual e de setores temáticos afins no universo da fantasia e da ficção científica.

Como subsetor na ficção científica e na fantasia contemporâneas, a realidade virtual integra um setor temático maior, o da realidade alternativa (ou mundo paralelo), que em muitos casos nada tem a 
ver com simulações por computador e é, na verdade, mais do que centenária como interesse temático (cf. por exemplo Alice no país das maravilhas, de Lewis Carroll, ou O castelo dos Cárpatos, de Júlio Verne). As finalidades de tal setor temático são diversas: criar um mundo diferente do real que funcione como utopia na qual se refugiar; construir uma impressão de algo sobrenatural que, a seguir, recebe uma explicação científica ou tecnológica (uma forma primitiva de cinema e de fonógrafo em O castelo dos Cárpatos, por exemplo); explorar a indagação acerca do que é 'verdadeiro' na realidade percebida e, em contraste, o que não passa de ilusão.

As principais razões que tornam atraente a temática da realidade virtual, em conjunto com outras similares que invocam realidades alternativas ou paralelas, parecem ser três.

Em certo sentido, as obras de ficção - romances, contos, filmes, histórias em quadrinhos, novelas ou séries televisivas - podem ser consideradas como uma espécie de realidade virtual com que interagem o autor e também o público (enquanto funcione a 'suspensão da incredulidade' sem a qual é impossível fruir uma história ficcional): autor e público, ao produzir e ao consumir tal obra, estão lidando com personagens e circunstâncias inventadas, nas quais se pode, no entanto, 'acreditar' até certo ponto. E o autor, em sua criação de pseudo-realidades, tem alguma semelhança com um demiurgo criador. Assim, ao tematizar realidades simuladas, mundos paralelos e outras modalidades do mesmo gênero ou similares, abre-se a possibilidade de uma interrogação metafórica sobre o próprio processo de criação, de autoria e de responsabilidade diante do que se criou (tais realidades outras com freqüência remetem à questão de quem ou o quê as gerou).

Também é factível usar temáticas assim para explorar visões mais ou menos carregadas de paranóia - a respeito da manipulação de indivíduos ou grupos por um poder que, pelo menos durante uma parte do enredo, não se deixa perceber, observar ou identificar. Entre outras possibilidades está a de examinar de um tal ângulo a sempiterna questão da alienação e da diminuição da liberdade individual no mundo contemporâneo.

Por fim, obras dotadas de um viés metafísico ou filosófico tratarão, mediante tal estratagema, de abordar perguntas sempre recorrentes acerca da realidade do mundo, do que torna tal realidade 'real', da diferença entre realidade e simulação (Clute \& Nicholls, 1995, p. 1285-6) etc.

Em ficção científica, todas estas possibilidades podem dar lugar a soluções diversas. Dentre elas, a temática específica da realidade virtual stricto sensu começou a tornar-se importante como artifício ficcional sobretudo a partir da década de 1980, acompanhando em especial os desenvolvimentos da informática. Deve-se entender, porém, termos aí a versão up-to-date de uma preocupação em si bem 
$2 \mathrm{O}$ método empregado (muito seletivamente) é descrito em Cardoso, 2001, p. 47-64. mais antiga. Já no século XIX, as reproduções cada vez mais fiéis de obras de arte, por exemplo, começavam a suscitar indagações acerca do que faz a diferença entre o original e suas cópias - uma preocupação que só fez aumentar e tornar-se multiforme desde então.

\section{Análise do filme 13ㅇaㅅ (The thirteenth floor), dirigido por Josef Rusnak (1998) ${ }^{2}$}

\section{Ficha técnica}

- Data: a produção começou em fevereiro de 1998; a estréia deu-se nos Estados Unidos em 28 de maio de 1999

- Estúdio: Centropolis Entertainment (distribuição pela Columbia Pictures)

- Produtores: Roland Emmerich, Ute Emmerich e Marco Weber

- Diretor: Josef Rusnak

- Roteiristas: Josef Rusnak e Ravel Centeno-Rodríguez

- Música: Harald Kloser

- Direção de Arte: Frank Bollinger

- Cenografia: Kirk M. Petrucelli

- Figurinos: Joseph Porro

- Edição: Henry Richardson

- Fotografia: Wedigo von Scheltzendorf

- Produtores de efeitos visuais: Henning Raedler e Christian Middelbery

- Coordenador de efeitos especiais: John S. Baker

Personagens e intérpretes principais:

- Douglas Hall (programador, em 1998) / John Ferguson (bancário, em 1937) / David (um homem de 2024): Craig Bierko

- Jane Fuller (mulher de 2024 passando, em 1998, por filha de Hannon Fuller) / Natasha Molinaro (funcionária de um supermercado, em 1998): Gretchen Mol

- Pai de Jane em 2024/Hannon Fuller (cientista, em 1998)/Grierson (comerciante, em 1937): Armin Mueller-Stahl

- Jason Whitney (especialista em informática, em 1998)/Jerry Ashton (barman, em 1937): Vincent D'Onofrio

- Detetive Larry McBain (em 1998): Dennis Haysberth

- Detetive Zev Bernstein (em 1998): Steven Schub

- Tom Jones (dono de um bar, em 1998): Jeremy Roberts

O filme foi examinado em formato widescreen anamórfico, usandose o DVD 02848 TNWS (Columbia TriStar Home Entertainment/ Sonypictures). 


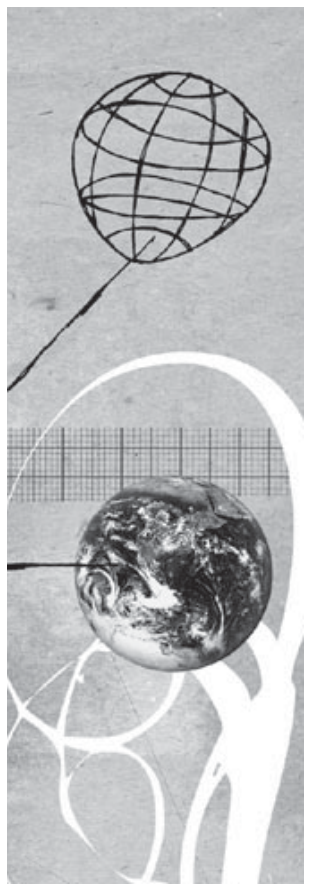

\section{Locais da ação e linhas narrativas:}

Linha narrativa 1: em uma Los Angeles utópica, em 2024 (funciona, no filme, como realidade futura)

Em 2024, Los Angeles conhece o ponto mais baixo de criminalidade de toda a sua história, como se lê num jornal. $\mathrm{O}$ aquecimento global elevou o nível do mar pelo derretimento das calotas polares e, com isso, o vale ocupado pela cidade foi inundado. Tal coisa, porém, dá à urbe a aparência de algo limpo, luminoso e arejado (em contraste com a poluída e superpovoada Los Angeles do presente), com os edifícios futuristas a se destacarem da água. Nesse mundo futuro, para finalidades de pesquisa, geraram-se milhares de realidades virtuais de grande perfeição, simuladas por computador e reconstituindo épocas variadas, com que as pessoas de 2024 podem interagir fazendo o seu download nas 'unidades' eletronicamente modeladas como seus correspondentes em cada uma dessas simulações.

Descobre-se que, na simulação de Los Angeles em 1998: 1) certas pessoas (unidades) criaram por sua vez uma simulação de Los Angeles como era em 1937; 2) alguém (Fuller, o principal criador da simulação de 1937) descobriu o caráter simulado de sua própria Los Angeles e pode propagar tal conhecimento. Um casal vinculado, no século XXI, ao projeto das simulações, David (cujo alter ego em 1998 é Douglas Hall, que trabalha com Fuller) e Jane (cujo alter ego na 1998 simulada é uma funcionária de supermercado, Natasha Molinaro, moça sem sofisticação que contrasta com a fina Jane), passa a fazer incursões à simulação de 1998 para resolver os problemas nela surgidos: ter-se criado aí outra simulação, da Los Angeles de 1937 (esta precisaria ser eliminada); o fato de uma e depois outras das unidades terem vindo a conhecer o caráter simulado de si mesmas e do mundo que as cerca deve ser revertido, já que isto anula as possibilidades de usar a simulação de 1998 na pesquisa para a qual foi suscitada.

David, entretanto, já não age de verdade para tais finalidades mas, sim, por motivos pessoais e para sua diversão, tendo-se tornado um maníaco homicida. No final, é substituído em 2024 por sua contrapartida de 1998 (tendo sido morto na Los Angeles simulada de 1998), Douglas Hall. Este descobre que, naquele mundo 'futuro', o pai de Jane é um alter ego de seu amigo e patrão (assassinado em sua versão de Los Angeles, a de 1998), Hannon Fuller. A última imagem do filme sugere que a própria Los Angeles de 2024 poderia ser uma simulação.

Linha narrativa 2: numa Los Angeles de 1998 que se descobre ser um simulacro gerado por computador (o presente do filme)

O cientista Hannon Fuller chefia uma corporação bilionária criada por sua iniciativa para fins de pesquisa cibernética, onde, 
3 O termo 'distopia', entendido como antônimo de 'utopia', foi cunhado em 1868 pelo filósofo e político britânico John Stuart Mill, entrando aos poucos na linguagem corrente primeiro nos países de língua inglesa - a partir de 1952. após seis anos de trabalho, assessorado por dois auxiliares principais, Douglas Hall e Jason Whitney, chegou à fase final do projeto em curso, tendo-se criado um simulacro eletrônico da Los Angeles de 1937 tal como a conhecera Fuller em sua juventude. Meses antes da data fixada para o começo das experiências dos cientistas na interação em interface direta com as 'unidades' que povoam a simulação de 1937, porém, Fuller inicia seu próprio download em sua contrapartida no simulacro, Grierson, para fins estritamente pessoais (fazer sexo com mulheres jovens). Tendo, além disto, descoberto ser seu próprio mundo um simulacro, ao tentar viajar para fora da Los Angeles de 1998 e notar que em certo ponto da estrada o mundo terminava, isto cria uma situação que faz intervir duas pessoas do futuro. Estas tratam de fechar o que era uma simulação (a de 1937) dentro de outra simulação, a Los Angeles artificial de 1998, bem como de eliminar o problema criado por algumas unidades terem percebido ser seu mundo uma simulação. Uma dessas pessoas de 2024, David, assassina Fuller e mais tarde a testemunha do primeiro assassinato, Tom Jones.

A partir daí, a linha narrativa de 1998 adquire um subtexto de film noir policial moldado em filmes e romances das décadas de 1930 e 1940: os detetives McBain e Bernstein, da Polícia de Los Angeles, trabalham para solucionar o crime cometido, tendo de início Douglas Hall como principal suspeito. Este último, vindo a saber que Fuller lhe deixara uma mensagem (apagada por David na secretária eletrônica de Hall) e conseguindo restaurá-la, desconfia a partir dela que a explicação esteja à sua espera na Los Angeles simulada de 1937, decidindo então visitá-la. Além do aspecto policial, a linha narrativa de 1998 é dominada pelo romance que se desenvolve entre Jane e Douglas e pelos esforços da primeira - que se faz passar por filha de Hannon Fuller - no sentido de encerrar o simulacro de 1937 fechando a corporação que o criara; tal tentativa é dificultada por Fuller, pouco antes de morrer, ter feito um novo testamento em que deixava a empresa para seus funcionários.

O desvelamento, tão típico do cyberpunk, aparece, então, em dois níveis: o da investigação policial de dois assassinatos; e o da progressiva descoberta, por Hall e depois por outros, de também a Los Angeles de 1998 em que vivem ser um mero simulacro, tal como a de 1937.

Linha narrativa 3: numa Los Angeles 'distópica', ${ }^{3}$ em 1937 (em plena depressão econômica da década de 1930) - utópica, porém, para Fuller -, que é um simulacro gerado por computador e, no filme, dá a impressão de situar-se no passado

Douglas Hall faz em duas ocasiões seu download em sua contrapartida de 1937, o bancário John Ferguson, interagindo localmente sobretudo com o alter ego de Fuller, o veterano de guerra e 
dono de loja de antigüidades Grierson, e com o violento barman e gigolô Jerry Ashley, que é a contrapartida de seu pacato colega e amigo Jason Whitney. Ashley se apossara de uma mensagem escrita que lhe fora confiada, no bar do Wilshire Grand Hotel, para ser entregue a Douglas Hall, por Fuller (que, ao 'entrar' em Grierson, usa seu nome de 1998 quando freqüenta um hotel-clube em busca de diversão) - querendo Fuller assegurar-se de que seu subordinado e amigo fosse informado de ser a Los Angeles de 1998, em que ambos vivem e trabalham, um simulacro, pois suspeita que os criadores de tal simulacro tratariam, talvez, de matá-lo por o ter descoberto. Lendo a mensagem que não lhe era destinada, a seguir constatando a transformação de Douglas Hall em sua contrapartida de 1937 (o bancário John Ferguson), por fim seguindo as instruções da carta de Fuller que roubara e, assim, percebendo ser impossível sair de verdade daquela Los Angeles simulada (pois em certo ponto da estrada atinge-se o 'fim do mundo'), Jerry Ashley descobre serem o mundo em que vive, bem como ele próprio, meras simulações. Por tal razão, ataca violentamente Hall (encarnado pela segunda vez em sua contrapartida de 1937, Ferguson).

Jason Whitney decide, por sua vez, visitar a Los Angeles simulada de 1937. Cria-se em função disto uma situação em que seu alter ego local, Jerry Ashley, é catapultado para a Los Angeles de 1998, devido à morte por atropelamento de Whitney na 1937 recriada em computador. A Los Angeles simulada de 1937 parece a Hall e depois a Jason Whitney perfeita (a não ser por certa imprecisão da luminosidade e das cores) e 'real', tanto no relativo ao cenário quanto às pessoas (unidades eletronicamente geradas). No entanto, em contraste com a atitude de Hall a respeito, Whitney não leva a sério o que ali ocorra, persistindo em perceber aquele mundo simulado como um jogo, uma imitação, e os humanos locais, como meras 'unidades' eletronicamente geradas.

Em plena depressão dos anos 30, trata-se de um local ideal onde achar moças belas e pobres (que trabalham no Wilshire Grand Hotel) com as quais fazer amor por dinheiro, o que foi aproveitado por Fuller, o principal criador do simulacro de 1937, sem afetar em 1998 a sua reputação.

\section{Análise}

A escolha, para análise, do filme $13^{\circ}$ andar (Josef Rusnak, 1998), em lugar, por exemplo, de The Matrix (Larry e Andy Wachowski, 1999), que teve um sucesso de público e uma repercussão muito maiores, deve-se a minha forte e decidida preferência pessoal por obras de ficção científica isentas de mesclas com outras formas de fantasia, artes marciais e pseudo-misticismo New Age. 


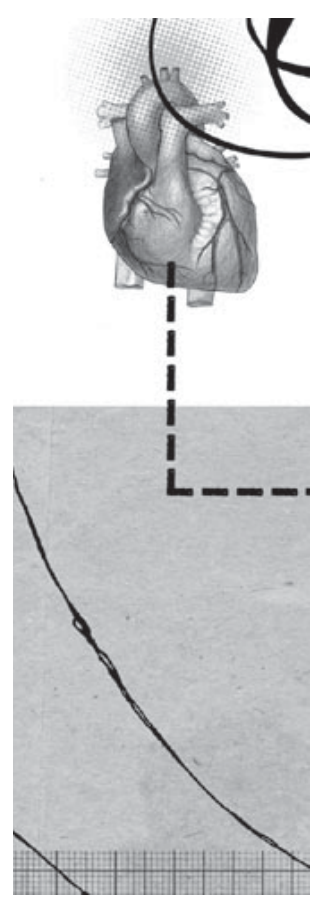

O filme do diretor alemão Josef Rusnak, que também atuou como co-roteirista, baseia-se no romance de ficção científica Simulacron 3, do escritor estadunidense Daniel F. Galouye (1920-1976), obra de 1964 que retoma uma temática desenvolvida, em 1954, por Frederik Pohl. O livro de Galouye já inspirara, na Alemanha Ocidental, uma minissérie de televisão, Welt am Draht (1973), dirigida por Rainer Werner Fassbinder. Daniel Galouye, romancista que produziu poucas obras em decorrência de uma saúde crescentemente frágil devido a feridas que recebera quando de sua participação na Segunda Guerra Mundial, estava, quanto ao assunto da realidade virtual, bem à frente da ficção científica de sua época. Em especial, prenunciava, em seus romances maduros, o melhor dos quais é exatamente Simulacron 3, as problemáticas em que se notabilizaria pouco depois Philip K. Dick (Clute \& Nicholls, 1995, p. 466; Murail, 1999, p. 154-5). O filme despolitiza consideravelmente a história contada por Galouye. É fiel a ela no tocante à realidade virtual, mas trata de atualizá-la para sua modalidade cyberpunk, inaugurada em 1982. A lógica e a estética do filme, entretanto, afastam-se do cyberpunk em pontos importantes (entre eles o fato de o futuro retratado não ser distópico e, sim, utópico, bem como a preferência por um visual clean - nada do lixo, da sucata e dos bandos de rua ameaçadores tão típicos do futuro tal como imaginado na década de 1980 e inícios da seguinte), apesar de uma continuidade indubitável em outros aspectos (por exemplo a preocupação com o desvelamento e a busca de uma temática e certos elementos visuais baseados nos films noirs). Filmes mistos em suas características tanto temáticas quanto estéticas, como o que nos interessa, na ausência de uma designação clara ou específica, costumam ser classificados como pós-cyberpunk.

Nos romances e filmes cyberpunk e posteriores extrapola-se, a partir dos jogos interativos de computador já existentes e da realidade virtual mais avançada disponível, baseada no uso de capacete e luvas com sensores vinculados a um programa, uma modalidade de realidade virtual ainda inexistente na atualidade: a interface eletrônica direta de um ser humano com uma programação de computador, por sua vez ligada a bancos de dados que permitam simular um mundo alternativo (o cyberspace ou ciberespaço). Como foi observado anteriormente, a ficção científica, apesar de sua denominação, não é de verdade, ou a fundo, científica. Assim, o fato de ficar o corpo daquele que 'navega' no ciberespaço numa espécie de catalepsia (alojando, enquanto dura a sessão, a personalidade de seu alter ego simulado), ao passo que o seu 'ser profundo', 'personalidade', 'alma' ou 'espírito' estiver vivendo na realidade alternativa, como ocorre no filme de Rusnak e em muitas outras obras ficcionais, tem a ver é com a dualidade cristã corpo/alma, matéria/ espírito; e, não, com a ciência, a que é estranha uma dualidade dessas. 
A interrogação sobre a realidade do mundo e acerca do que constitui um ser humano é um antigo problema, tanto científico quanto filosófico, já o mencionamos. Como garantir a realidade do mundo se só o podemos perceber por meio de sentidos imperfeitos? Assim sendo, que diferença perceptível, comprovável na prática, haveria entre o mundo que achamos existir e no qual vivemos, e outro, 'simulado', em que, mediante inputs eletrônicos, cada 'unidade' pseudo-humana pensasse ter um corpo e agisse autonomamente num mundo para ela real, no qual desempenhasse as diferentes funções consideradas humanas? E, sendo o homem ao mesmo tempo um animal e algo diferente (um ser dotado de consciência, de sofisticados sistemas de comunicação e programação, e de cultura), qual é a essência do humano? Daí, em diferentes épocas e contextos, ter-se valorizado o homo faber (produtor de ferramentas, de artefatos artificiais), o homo religiosus, o homo politicus, o homo oeconomicus ou o homo symbolicus - todos eles meras construções unilaterais - como a mais importante faceta de uma 'natureza humana' inefável.

A possibilidade mais interessante filosoficamente (como problema ontológico, da teoria do conhecimento, ou de diferentes metafísicas), ao utilizar-se ficcionalmente da realidade virtual, é a que caracteriza o filme que analisamos, voltado para indagações como: o que é o mundo real? o que é um ser humano real? A ancoragem de $13^{\circ}$ andar em tal problemática é explícita. A última imagem do filme sugere que o mundo de 2024, o único que, no desenrolar da ação, jamais fora apresentado como um simulacro, poderia, apesar de tudo, ser exatamente isso. E, no entanto, em suas três versões, o mundo parece de todo real aos que nele vivem - com exceção de uns poucos dentre estes últimos.

A epígrafe do filme é a conhecida frase de Descartes: "Penso, logo existo" - o que mostra que o roteirista-diretor pende para uma definição do humano mais ampla ou maleável do que a habitual. As 'unidades' que povoam as simulações que o filme mostra (a de 1998 e a de 1937) são, sem dúvida, descritas como 'seres cibernéticos', 'personagens eletronicamente simuladas', 'feixes de circuitos eletrônicos', 'uma simulação dentro de um computador'; uma delas, consciente de tal estado de coisas, declara: "se alguém puxar a tomada, eu desaparecerei". No entanto, tais entidades pensam, comem, fazem amor, trabalham, sangram e morrem. Jane, a mulher do futuro, ama a 'unidade' Douglas Hall; seu marido David a acusa, por tal razão, de "apaixonar-se por uma maldita simulação". Mas quando Douglas lhe pergunta como pode ela amá-lo, não sendo ele nem mesmo real e, como uma marionete, estando desprovido de 'alma', ela lhe responde: "Você é mais real para mim do que qualquer outra coisa que eu conheça"; e declara que a prova de possuírem, ele e Fuller, 'alma' ou consciência, de serem agentes 
autônomos dotados de livre-arbítrio, era terem descoberto por si mesmos que eles e seu mundo tinham sido artificialmente criados.

Para salientar esse aspecto do livre-arbítrio, neste filme, como em outras obras pertencentes à mesma linha temática, os seres gerados eletronicamente, quando não estão 'possuídos' pelas contrapartidas que os modelaram, delas se afastam muito em personalidade, caráter, ações e peculiaridades pessoais (penteado, modo de vestir, gestos etc.). $\mathrm{O}$ contraste mais gritante no filme, nesta ordem de idéias, é o que existe entre o pacífico Whitney e seu violento alter ego Ashton.

O próprio Douglas, ao voltar de sua primeira incursão a 1937, diz a Jason Whitney sobre as 'unidades' com que interagiu: "Eles são tão reais quanto você e eu" (já que naquele momento ainda não descobrira serem ambos, igualmente, unidades eletronicamente criadas); e, ao voltar da segunda incursão, mesmo sabendo o que agora sabe sobre 1937 e 1998, afirma: "Estamos interferindo na vida de pessoas". Em 1937, Jerry Ashley, tendo baleado Hall/Ferguson, lhe pergunta: “O que é real? Este sangue é real?". O detetive McBain, quando descobre, por sua vez, ser sua Los Angeles um simulacro, pede a Jane que cesse de interferir com aqueles que a povoam.

Além da temática realidade versus simulacro, o filme também investe em outro assunto predileto do cyberpunk: a manipulação. Todo poder, ao ser exercido, manipula e corrompe. Isto é ilustrado pelo fato de tanto Fuller, com seu ar de paizão pacato e bonachão, quanto o maníaco David perverterem os projetos que geraram simulacros destinados à pesquisa, ao usarem estes últimos para seus próprios fins pessoais pouco dignos.

The Matrix (Larry e Andy Wachowski, 1999), Cidade das sombras (Alex Proyas, 1997), o filme que analisamos e alguns outros podem ser interpretados como criações de um cinema auto-reflexivo, ou seja, um cinema comercial que aceita por fim ver a si mesmo como produtor de ilusão e manipulação, em contraste com a atitude passada que, quase sempre, consistia em procurar dissimular tais aspectos em favor da 'ilusão de realidade' buscada tradicionalmente pelo cinema comercial clássico.

No tocante aos recursos e efeitos utilizados no filme, farei três observações.

A distinção visual entre os três mundos - de 1937, de 1998 e de 2024 -, de que depende toda a estética do filme, foi obtida mediante variações cuidadosamente calculadas e processadas (por vezes em laboratório) das cores e da iluminação; pelos cenários, roupas, mobília e outros acessórios fortemente contrastantes; bem como por opções bem definidas de foco e manejo de câmera em cada caso.

O salão de baile do Wilshire Grand Hotel foi instalado dentro do navio Queen Mary (construído em 1934), ancorado em Long Beach, para aproveitar as paredes decoradas e as grandes luminárias 


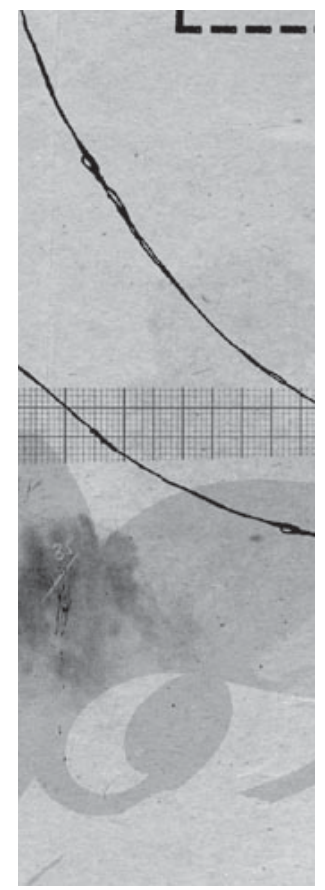

circulares do teto de seu enorme salão de festas. Kirk M. Petrucelli e seus colaboradores fabricaram o bar com espelhos em relevo e o palco onde toca a orquestra, além de instalarem as mesas de jantar.

A recriação dos exteriores de Los Angeles em 1937 foi feita filmando as ruas como eram em 1998 (enchendo-as, porém, de carros antigos - mais de 40 - e de extras - cerca de 300 - vestidos com trajes dos anos 30, além de outros detalhes: jornais de 1937, por exemplo). A seguir, mediante programa de manipulação de imagens no computador, sua aparência foi modificada pela eliminação de prédios posteriores e inserção de reproduções das fachadas de prédios que existiam na década de 1930 (mediante fotos que deram lugar à fabricação de maquetes) mas foram sendo derrubados nas décadas seguintes.

Detalhe curioso, em se tratando de um filme que deve muitos de seus elementos ao cyberpunk, é que o futuro (situado no século XXI) seja totalmente utópico e, não, distópico: a distopia é transportada para as realidades simuladas de 1998 e 1937 (na prática, então, para o presente e o passado). Em se tratando de um futuro não tão distante, isto levaria à interrogação de como, tendo como ponto de partida um presente como o de 1998 mostrado pelo filme, poder-se-ia chegar, em menos de três décadas, à utopia de 2024. Uma resposta seria que a catástrofe que se adivinha pela invasão da cidade pelo mar tenha resolvido, em sua intensidade, muitos dos problemas, como os da superpopulação e da poluição. Outra possibilidade é que, se acreditarmos no que sugere a última imagem do filme, também tal 'realidade' de 2024 seja na verdade uma simulação, planejada exatamente para parecer-se a uma Los Angeles utópica.

\section{Conclusão}

A segunda metade da década de 1990 - a mesma época, portanto, em que começaram a surgir os filmes que focalizamos, em que o mundo revelava-se simulado - viu reaparecerem filmes de vocação militarista e ufanista, reivindicadores da legitimidade do establishment estadunidense e reminiscentes do espírito dos anos 50 , sempre mediante situações ficcionais que permitissem e mesmo solicitassem extenso uso de efeitos especiais espetaculares. São filmes em que os Estados Unidos salvam o mundo de alguma ameaça: alienígenas invasores (Independence day, de Roland Emmerich, 1996); um cometa ou asteróide que ameaça fazer impacto com nosso planeta, elemento inspirado pela teoria da extinção dos dinossauros exatamente por um fenômeno similar (Armageddon, de Michael Bay, 1998; Impacto profundo, de Mimi Leder, 1998). Tais produções, que podem até certo ponto interpretar-se como uma comemoração da vitória ocidental na Guerra Fria - algo evidente desde 1989-1991 -, diferenciam-se das de meados do século XX por sua 
insistência no 'politicamente correto' (Impacto profundo, de tal ponto de vista, parece perfeito: a protagonista é uma mulher e o presidente dos Estados Unidos é negro) e por apresentarem, apesar de tudo, certa ambigüidade diante do sistema que defendem. Além do mais, retomam o 'cine-catástrofe' da década de 1970, o qual longe estava de ser utópico. São, também, minoritárias no output do cinema de ficção científica dos Estados Unidos.

De maior interesse é a clara continuação da distopia cyberpunk, se bem que com um menor grau de politização em muitos casos, bem como investindo numa estética distinta em diversos pontos. Permanecia forte, então, no final da década passada, a noção - realista - de que, do presente tal como é, dificilmente poderão derivar futuros de signo positivo. E o que o futuro teria de mais negativo, numa época narcisista, era visto como a opressão da liberdade e das escolhas dos indivíduos. Afinal, no mundo pós-Guerra Fria dominam concepções e regimes neoconservadores que exaltam o mercado mas não tanto a democracia, em que enxergam 'exageros perigosos', e menos ainda se preocupam com a preservação da autonomia e dos direitos individuais. Em minha opinião, o melhor filme foi, aqui, Gattaca: a experiência genética (direção e roteiro de Andrew Niccol, 1997), um raro exemplar de ficção científica extremamente inteligente e livre de qualquer mescla com misticismo, capa e espada ou artes marciais; o qual, no entanto, ao não insistir em efeitos especiais espetaculares, teve um sucesso limitado de público.

Dentro de uma visão majoritariamente distópica do presente ou do futuro próximo, muito centrada na noção de os indivíduos se sentirem manipulados e diminuídos em suas liberdades e iniciativas, uma tendência importante é a que manifesta preocupação com a relação entre realidade e simulacro, explorada mediante o recurso à noção de 'realidade virtual'. O filme de maior repercussão foi, neste caso, The Matrix (de Larry e Andy Wachowski, 1999), que no entanto, a meu ver, tem falhas consideráveis na linha narrativa e faz excessivas concessões à moda das artes marciais, misturada a um pseudo-misticismo New Age, algo bem presente desde as duas trilogias de Guerra nas estrelas. Bastante melhor, na mesma temática, é $13^{\circ}$ andar (Josef Rusnak, 1999), que analisamos; um filme que apresenta, entretanto, a peculiaridade de que, após hesitações, sua equipe produtora acabou optando por apresentar um futuro utópico.

\section{REFERÊNCIAS BIBLIOGRÁFICAS}

Blackburn, Simon 1997

Bova, Ben 1993
Dicionário Oxford de Filosofia.

Trad. Desidério Murcho et al. Rio de Janeiro: Jorge Zahar.

Challenges.

New York: Tor. 
Bunge, Mario

1985

Cardoso, Ciro

Flamarion

2003

Cardoso, Ciro

Flamarion

2001

Clute, John; Nicholls,

Peter (org.) 1995

Goimard, Jacques 2002

Goimard, Jacques 1976

Le Guin, Ursula K. 1976

Lem, Stanislaw 1997

Lem, Stanislaw

1983

Lem, Stanislaw 1982

Mann, George (org.) 2001

Murail, Lorris 1999

Okuda, Michael; Okuda, Denise; Mirek, Debbie 1994
Racionalidad y realismo.

Madrid: Alianza Editorial.

A ficção científica, imaginário do mundo contemporâneo: uma introdução ao gênero. Niterói (RJ): Vício de Leitura.

Ensayos.

San José: Editorial de la Universidad de Costa Rica.

The encyclopedia of science fiction.

New York: St. Martin's Griffin.

Critique de la science-fiction.

Paris: Pocket.

Une définition, une définition de la définition, et ainsi de suite.

Cinéma d'aujourd'hui, n. 7, p. 11-20.

Introduction. The left hand of darkness.

New York: Ace Books. (Páginas não numeradas.)

A Stanislaw Lem reader. Compilado por Peter Swirski. Evanston (Ill):

Northwestern University Press.

Solaris.

Trad. Inês Busse. Lisboa: Ed. Europa-América.

Memoirs of a space traveler: further reminiscences of Ijon Tichy.

Trad. Joel Stern e Maria Swiecicka-Ziemianek. San Diego (Cal):

Harcourt Brace Jovanovich.

The mammoth encyclopedia of science fiction.

New York: Carroll \& Graf.

La science-fiction.

Paris: Larousse.

Star Trek encyclopedia: a reference guide to the future.

New York: Pocket Books.

Recebido para publicação em agosto de 2006.

Aprovado para publicação em setembro de 2006. 